\title{
Patient satisfactionand psychological well-being after internet-based cognitive behavioral stress management (IB-CBSM) for women with preterm labor: a randomized controlled trial
}

Scherer (M.Sc.) $)^{1}$, S., Alder (PD Dr. phil.)², J., Gaab (Prof. Dr. phil.)2, J., Berger (Prof. Dr. phil.) $)^{3}$, T., Ihde (M.Sc.) $)^{2}$, K. \& Urech (Dr. phil.) $)^{1}$, C.

${ }^{1}$ Women's Hospital, University Hospital Basel, Switzerland

${ }^{2}$ Clinical Psychology and Psychotherapy, Department of Psychology, University of Basel, Switzerland ${ }^{3}$ Clinical Psychology and Psychotherapy, Department of Psychology, University of Bern, Switzerland

Corresponding author

Sandra Scherer, M.Sc.

Gyn. Sozialmedizin und Psychosomatik, Universitäts-Frauenklinik Basel, Spitalstrasse 21, CH-4031 Basel, Tel.: +41 (0)61 55657 62, Fax: +41 (0)61 26590 35, sandra.scherer@usb.ch

(C) 2015. This manuscript version is made available under the Elsevier user license http://www.elsevier.com/open-access/userlicense/1.0/ 


\section{ABSTRACT}

Objective and methods:Despite its value for the management of psychological burden, little is known about the efficacy of and patient satisfaction withinternet-based cognitive behavioral stress management (IB-CBSM) for women with preterm labor. The present study sets out to analyze stress/anxiety reduction, patient satisfaction and patient's working alliance in a group of 58 women with preterm labor participating in an online psychological stress management project. As part of the project, women were randomly assigned to online stress management or a control condition.

Results: Levels of stress and anxiety decreased significantly in both conditions from pre- to post-treatment measure.Participants in IB-CBSM reported significant higher working alliance inventory (WAI) scores in the task and goal subscale $(\mathrm{p}<.001 ; \mathrm{p}<.05)$ than women in the control condition. In Addition theIB-CBSM groupshowed significant correlations of the WAI subscale task and goal and the stress/anxiety outcome. Regarding patient satisfaction, women in the IB-CBSM reportedsignificantly higher satisfaction $\operatorname{scores}(\mathrm{p}<.001)$ than women in the control condition. WAI explained nearly $40 \%$ of the variance in patient satisfaction. Furthermore, WAI mediates, at least in part, the relationship between group condition and patient satisfaction.

Conclusion:The current analysis indicated that participants in IB-CBSM had higher WAI scores and were more satisfied with the program. In addition only theIB-CBSM groupshowed significant correlations of the WAI with the stress/anxiety reductionoutcome.Based on these findings, it can be presumed that measures of agreement with working alliance parameters, especially task and goal components, are substantially importantfor more effective and satisfactory therapeutic interventions.

\section{KEYWORDS}

Internet-based stress management, patient satisfaction, preterm labor, stress/anxiety reduction, 
working alliance, psychological well-being 


\section{INTRODUCTION}

Preterm birth (PTB), defined as delivery before week 37 of gestation, occurs at a rate ranging from $5 \%$ to $18 \%$ according to current worldwide data(1). About $40-50 \%$ of PTBs are idiopathic and result from spontaneous preterm labor (PTL) (2). Besides being linked to various medical risk conditionssuch as infections,inflammations andhemorrhages (3), PTL is also associated with physiological, psychological, and psychosocial factors of stress and anxiety(4, 5).An effective approach to reduce psychological burden and improve quality of life are psychological interventions based on cognitive behavioral stress management $(\mathrm{CBSM})(6,7)$. Also during pregnancy, indicated treatment interventions showed positive effects in reducing maternal distress(8). However, since women with PTL are often limited in their mobility, the delivery of these interventions is impeded by the underlying medical condition. In recent years, internet-based (IB) interventions have received more and more attention. Systematic reviews and meta-analyses support that IB treatments showed positive outcomes regarding psychological distress (symptoms of anxiety and depression, posttraumatic stress and medical-considered problems, e.g. chronic back pain and headache)(9-11).Therefore, IB-CBSMhas the potential to be an important component of the psychosocial management of PTL.Nevertheless, little is known about the feasibility of such interventions during pregnancy and about patient satisfaction with these interventions.

The concept of patient satisfaction is defined as the extent to which treatment meets the wishes and needs of patients(12).If patient satisfaction ratings are recorded, an insight into the patient's perspective is gained that supplements the conventional outcome measures (13).Previous studies regarding medical interventions have shown associations between patient satisfaction andcompliance (14), adherence to treatment, health-related quality of life(15)andsymptomatic improvement(16).

The patient-provider relationship, in particular, is often discussed as a possible factor thatcould partially affectthe relation between patient satisfaction and symptom reduction(17). 
Elements such as the patient's trust and confidence in the provider(18) and the extent of their agreement with the form of treatment (17)also seem to have a considerable impact on patient satisfaction. The concept of working alliance, which highlights the relationship between two individuals involved in a working process, is often used to observe these different aspects of alliance. Surprisingly, these elements often have an equal or even a higher impact on patient satisfaction than improvement of symptoms(17).For example, it was found that the relationship between working allianceand patient satisfaction was more pronounced than the association of symptom reduction and patient satisfaction(19).

With regard to therapy outcome, working alliance seems to be particularly important. In faceto-face settings,positiveandrobustassociationsbetweenthetherapeutic

allianceandtreatmentoutcomeformanydifferenttypesoftherapeuticinterventionswere recorded $(20,21)$. Although body of research on working alliance is steadily growing also in online interventions, only few empirical studies exist that specifically focus on the therapeutic alliance and its relationship with therapy outcomein this specific setting (22). Nevertheless,former resultsindicate that in IBtreatments therapeutic alliance is also evaluated comparatively high(23)and thatin some IB treatmentspositive associations between alliance and therapy outcome exist(24).Based on these findings, we set out toexaminestress/anxiety reduction,patient satisfaction and patient's working alliance with an internet-based stress management (IB-CBSM) for a group of pregnant women with PTL. The current paper focus on the associations between working alliance and the outcome parameters stress/anxiety reductionand patient satisfaction, further the predictive value of working alliance, symptom reduction and group for patient satisfactionwill be examined.

\section{METHODS}

The present study was part of the randomized controlled trial 'Stress and anxiety reduction in women with PTL to improve outcome: a randomized controlled intervention study' that set 
out to evaluate the efficacy ofinternet-based cognitive behavioral stress management (IBCBSM)in comparison to an active control condition in women with preterm labor. The impact of the IB-CBSM on gestational and biological stress outcomes will be presented in a separate paper. For further information see Scherer et al. (25).

\section{Participants and Inclusion Criteria}

The sample consisted of 93 pregnant women between gestational ages of 18 to 32 weeks suffering from medically diagnosed PTL. Excluded were high-risk patients with severe medical complications (e.g.,placenta praevia, uterine and cervical anomalies, current vaginal bleeding, severe infections, premature rupture of membranes and fetal malformations) as well as women with a positive screening for psychosis, suicidal tendencies or substance abuse disorder (with the exception of nicotine). The medical situation was assessed together with the monitoring physician in charge of prenatal care.

\section{Procedure}

Information concerning the study was published in pregnancy-specific magazines and sent to gynecological professionals at specific organizations and institutes. Interested women could contact the research team through the website or by telephone. Participants were provided with detailed information and the terms of participation. The local ethics committee approved the study protocol and a written release from medical confidentiality as well as the written informed consent form was collected from all participants. General information on demographics and mental health as well as pre-treatment distress level of stress and anxiety was gathered and assessed. After screening, participants were randomly assigned to the IB-CBSM or the control condition. A random assignment list was prepared within the website random.org. After module 2, 3, 4 and 5, participants were requested to evaluatethe perceived working alliance. After the last module, participants completed the post-treatment measure regarding distress level of stress and anxiety as well as satisfaction with the program. After 
birth, detailed pregnancy and birth outcome data were collected together with the monitoring medical professional.

\section{Intervention}

The six core IB-CBSM modules are based on elements of stress management training by Kaluza(6). The modules consisted of predetermined units (psychoeducational information, relaxation exercises) and interactive exercises (coping cards to reappraise stressassociatedthoughts)as well as protocols (activity diary, stress and problem solving protocol; cf.(25)). The contents of theIB-CBSM trainingwereillustrated with pregnancy specificissues and examplesand have been adapted to the situation of women with PTL. Thesixmodules were built on each other and were processedinthe intended order(weekly entering anew module).The IB-CBSM also included guidance which consisted ofa regular written exchange between the participant and her therapist (trained psychologist or a psychologist-to-be under supervision). Apart from answering questions, this concept contained a weekly feedback.Additionally, the participants had the opportunity to pose pregnancy-specific questions to the study team's midwife.The internet-based control condition was similar in format (also 6 modules) and involved exercises such as sudoku, riddles and writing stories. In the control condition the support provided was limited to instructions in these distraction strategies.

\section{Measures}

Two parameters served as the primary outcome. First, stress/anxiety reductionwas measured using the Perceived Stress Scale and the Spielberger State-Trait Anxiety Inventory. The Perceived Stress Scale (PSS)(26)is a commonly used self-assessment scale measuring the perception of stress. The scale reveals adequate values regarding validity andreliability (Cronbach's $\alpha>0.84$ ).Spielberger's State-Trait Anxiety Inventory (STAI)(27)assesses both current state and general traitanxiety. The questionnaire has been validated in German(28)showing high internalconsistency (Cronbach's $\alpha=0.90-0.94$ (state) and 0.88 
(trait)).

Second, the overall satisfaction with the programwasassessed by the German version of the Client Satisfaction Questionnaire CSQ-8 (29, 30). The original questionnaire shows an acceptable internal consistency (Cronbach's $\alpha=.93$ ) (30). Each item is scored on a 4-point Likert-scale and higher scores indicate higher satisfaction. The 8-item version used in the current study was adapted to the online program for women with PTL, asking specifically about satisfaction with the provided online program (appendix A).

The secondary outcome for our analysis was working alliance. Working alliance was assessed via the short and revised form of the working alliance inventory WAI-SR(31). The WAI-SR is a 12-item self-reporting questionnaire, based onBordin`s model of alliance(32). Each item is scored on a 5-point Likert-scale ranging from 1 (never) to 5 (always). The questionnaire has been validated in German(33) with a good reliability (Cronbach $\alpha=.80)(34)$. The questionnaire was adapted to the provided online help for women with PTL(35). Each question of the goal and task scale of the WAI-SR was adjusted by asking for the agreement with goal and task components of the online program. The items of the bond scale have been adapted in order that they relate to the perceived alliance between the participant and the therapist, providing the program contact (appendix B).

\section{Analysis}

93 women were eligible for participation and started intervention. 35 of these women dropped out before post assessment, and had to be excluded (c.f. Figure 1).To investigate whether there are differences between women who completed the post assessment and women who did not drop-out analyses were performed. Residual gain scores were calculated for PSS, STAI-S and STAI-T (difference of pre- vs. post-treatment PSS and STAI-S/T scores). Additionally, an overall variable that indicated stress and anxiety symptom reduction was constructed (sum of all residual gain scores) anda mean-score of overall satisfaction was calculated.A total WAI score and a total score for each subscale of the WAI was computed by determining an overall 
variable of the mean WAI scores of all four assessments. Group differences in baseline characteristics were tested with independent samples T-tests, Mann Whitney U tests and Chi square tests. Difference in stress and anxiety was measured with a two-way repeated analysis of variance. Group differences in patient satisfaction and WAI were calculated using independent samples T-tests and Mann Whitney U tests.To examine the associationsbetween working alliance and the outcome parameters stress/anxiety reductionand patient satisfaction bivariate correlations (Pearson and Spearman) were calculated. Hierarchical linear regression (method enter)was used, to test whetherthe variables WAI, group and symptom reduction have an influence on patient satisfaction. Mediation analyses were examined using the bootstrapping method with bias-corrected confidence estimates (95\% confidence interval, 5000 bootstraps resamples (36)). To investigate how patient satisfaction might be expressed as a function of working alliance over time and group, a two-way analysis of variance was applied. Therefore, WAI ratings after module 2-5 were further splited over the median into two groups (low vs. high WAI).Statistical analyses were performed using SPSS, version 22. Level of significance was set on a 5\% significance level for all analyses.Effect sizes were computed as Cohen's d(37), based on the pooled SD. 
Figure 1: Recruitment and participants flow-chart

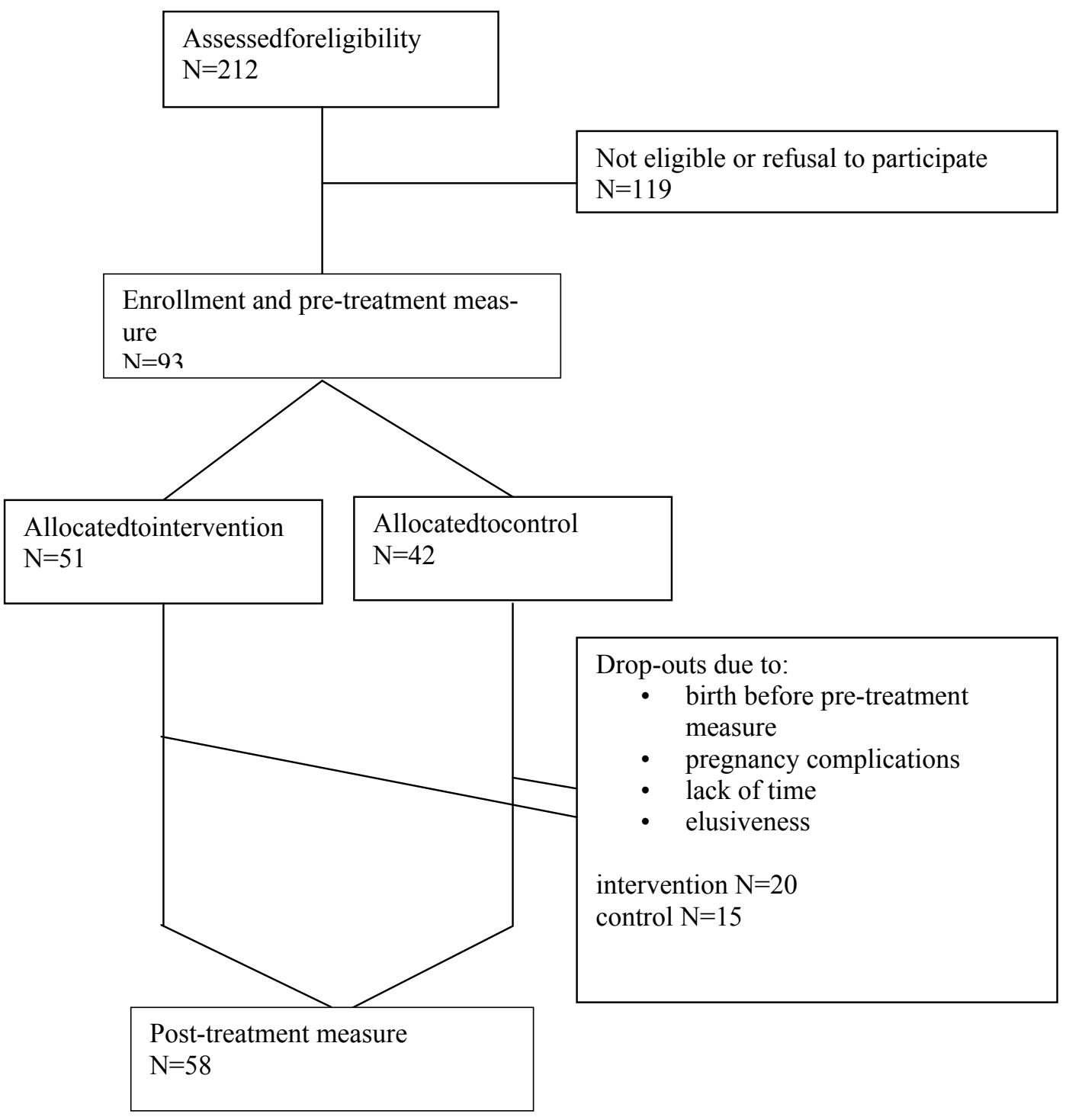

\section{RESULTS}

Drop-out analyses revealed no differences between completers and drop-outs in demographic characteristics, pre-treatment stress and anxiety scores or working alliance (Table I). Therefore statistical analyses were performed with the completer's dataset consisting of 58 women. Sample characteristics of the women in the completer's dataset are presented in Table 
II. 31 participants were randomly assigned to the IB-CBSM, 27 to the control condition.Most womenlived in Germany, were married and had no living child at the time of their pregnancy.About $90 \%$ of the participants reported a high educational level.Women in the IBCBSM and the control condition did not differ in any of the assessed demographic variables.

Table I: Drop-out analyses

\begin{tabular}{|c|c|c|c|c|}
\hline & Total & Completer & Drop-out & Sig. (p) \\
\hline Sample size N & 93 & 58 & 35 & \\
\hline Age in years & $32.68(3.70)$ & $32.53(3.49)$ & $32.91(4.08)$ & $.634(\mathrm{NS})$ \\
\hline $\begin{array}{l}\text { Gestational week at time of } \\
\text { program start }\end{array}$ & $28.43(3.27)$ & $28.69(2.75)$ & $28.00(3.99)$ & $.372(\mathrm{NS})$ \\
\hline Nationality & & & & $.790(\mathrm{NS})$ \\
\hline German & $50(53.8)$ & $32(55.2)$ & $18(51.4)$ & \\
\hline Swiss & $30(32.2)$ & $19(32.8)$ & $11(31.4)$ & \\
\hline Other & $13(14.0)$ & $7(12.0)$ & $6(17.2)$ & \\
\hline Marital status & & & & .099 (NS) \\
\hline Married & $71(76.3)$ & $41(70.7)$ & $30(85.7)$ & \\
\hline Unmarried & $22(23.7)$ & $17(29.3)$ & $5(14.3)$ & \\
\hline Education & & & & $.372(\mathrm{NS})$ \\
\hline University & $60(64.5)$ & $38(65.5)$ & $22(62.9)$ & \\
\hline $\begin{array}{l}\text { Secondary school, college and } \\
\text { higher vocational training }\end{array}$ & $20(21.5)$ & $14(24.2)$ & $6(17.1)$ & \\
\hline Vocational training & $13(14.0)$ & $6(10.3)$ & $7(20.0)$ & \\
\hline Number of children & & & & .419 (NS) \\
\hline None & $58(64.4)$ & $38(65.5)$ & $20(57.1)$ & \\
\hline One or more children & $35(37.6)$ & $20(34.5)$ & $15(42.9)$ & \\
\hline PSS pre-treatment & $70.07(16.40)$ & $69.28(15.97)$ & $71.37(17.25)$ & $.553(\mathrm{NS})$ \\
\hline STAI-S pre-treatment & $50.34(12.55)$ & $48.45(10.95)$ & $53.49(14.45)$ & $.079(\mathrm{NS})$ \\
\hline STAI-T pre-treatment & $43.32(10.89)$ & $42.50(10.81)$ & $44.69(11.04)$ & .351 (NS) \\
\hline WAI after module 2 & $3.20(0.76) \mathrm{N}=53$ & $3.21(0.74) \mathrm{N}=42$ & $3.18(0.87) \mathrm{N}=11$ & $.925(\mathrm{NS})$ \\
\hline WAI after module 3 & $3.29(0.74) \mathrm{N}=49$ & $3.24(0.77) \mathrm{N}=41$ & $3.53(0.55) \mathrm{N}=8$ & $.315(\mathrm{NS})$ \\
\hline WAI after module 4 & $3.59(0.64) \mathrm{N}=43$ & $3.59(0.67) \mathrm{N}=39$ & $3.50(0.25) \mathrm{N}=4$ & .579 (NS) \\
\hline WAI after module 5 & $3.56(0.79) \mathrm{N}=40$ & $3.55(0.81) \mathrm{N}=37$ & $3.81(0.46) \mathrm{N}=3$ & $.587(\mathrm{NS})$ \\
\hline
\end{tabular}

Note: NS, Not significant 
Table II: Demographic characteristics,completer's dataset

\begin{tabular}{|c|c|c|c|c|}
\hline & IB-CBSM & Control & Total & Sig. (p) \\
\hline Sample size N & 31 & 27 & 58 & \\
\hline Age in years & $32.90(3.49)$ & $32.11(3.50)$ & $32.53(3.49)$ & $.393(\mathrm{NS})$ \\
\hline $\begin{array}{l}\text { Gestational week at } \\
\text { time of program start }\end{array}$ & $28.32(2.96)$ & $29.11(2.47)$ & $28.69(2.75)$ & $.280(\mathrm{NS})$ \\
\hline Nationality & & & & $.592(\mathrm{NS})$ \\
\hline German & $19(32.8)$ & $13(22.4)$ & $32(55.2)$ & \\
\hline Swiss & $9(15.6)$ & $10(17.2)$ & $19(32.8)$ & \\
\hline Other & $3(5.1)$ & $4(6.9)$ & $7(12.0)$ & \\
\hline Marital status & & & & $.268(\mathrm{NS})$ \\
\hline Married & $20(34.5)$ & $21(36.2)$ & $41(70.7)$ & \\
\hline Unmarried & $11(19.0)$ & $6(10.3)$ & $17(29.3)$ & \\
\hline Education & & & & $.511(\mathrm{NS})$ \\
\hline University & $22(37.9)$ & $16(27.6)$ & $38(65.5)$ & \\
\hline $\begin{array}{l}\text { Secondary school, } \\
\text { college and higher } \\
\text { vocational training }\end{array}$ & $7(12.1)$ & $7(12.1)$ & $14(24.2)$ & \\
\hline Vocational training & $2(3.4)$ & $4(6.9)$ & $6(10.3)$ & \\
\hline Number of children & & & & $.864(\mathrm{NS})$ \\
\hline None & $20(34.5)$ & $18(31.0)$ & $38(65.5)$ & \\
\hline $\begin{array}{l}\text { One or more } \\
\text { children }\end{array}$ & $11(19.0)$ & $9(15.5)$ & $20(34.5)$ & \\
\hline
\end{tabular}

Note: NS, Not significant

\section{Stress/anxiety reduction, patient satisfaction and working alliance}

Levels of stress and anxiety decreased significantly in both conditions from pre- to posttreatment measures(PSS: $F(1,50)=37.287, \mathrm{p}<.001$; STAI-S: $\mathrm{F}(1,50)=40.140, \mathrm{p}<.001$; STAI-T: $\mathrm{F}(1,50)=15.586, \mathrm{p}<.001)$. All analysis showed no group differences or group $\mathrm{x}$ time effects(PSS: $\mathrm{F}(1,50)=.182, \mathrm{p}=.672$; STAI-S: $\mathrm{F}(1,50)=.109, \mathrm{p}=.743$; STAI-T: $\mathrm{F}(1,50)=.539$, $\mathrm{p}=$.466).Participating women showed high (IB-CBSM: $\mathrm{M}=3.41, \mathrm{SD}=.44)$ to moderate (control condition: $\mathrm{M}=2.82, \mathrm{SD}=.58$ ) patient satisfaction according toTempier et al. and Greenwood et al.(38, 39). The referred WAI ratings indicated high (IB-CBSM: M=3.51, SD=.69) and medium (control condition: $\mathrm{M}=3.05, \mathrm{SD}=.72$ ) working alliance values as defined by Jasper et al.(40). Women in the IB-CBSM reported statistically significant higher patient satisfaction $(\mathrm{U}(27,31)=165, \mathrm{p}<.001$; Cohen's $\mathrm{d}=1.15)$ and overall WAI scores $(\mathrm{t}(56)=2.476, \mathrm{p}=.016$; 
Cohen's $\mathrm{d}=.65$ ) than participants in the control condition. Results of the WAI subscales analyses showed that participants in the IB-CBSM group rated working alliance in the subscale task $(\mathrm{t}(56)=3.820, \mathrm{p}<.001 ;$ Cohen's $\mathrm{d}=1.00)$ and goal $(\mathrm{t}(56)=2.377, \mathrm{p}=.021$; Cohen's $\mathrm{d}=.63$ ) significantly higher than the participants in the control condition, whereas the bond scale showed no differences between the groups $(U(27,31)=370, p=.449$; Cohen's $\mathrm{d}=.12)$ (Table III).

Table III: Stress, anxiety, satisfaction andworking alliance (between group differences)

\begin{tabular}{|c|c|c|c|c|c|}
\hline & $\mathrm{N}$ & IB-CBSM (M, SD) & Control (M, SD) & Total (M, SD) & Sig. (p) \\
\hline Sample size & & 31 & 27 & 58 & \\
\hline PSS pre-treatment & 58 & $69.23(17.46)$ & $69.33(14.39)$ & $69.28(15.97)$ & .980 (NS) \\
\hline STAI-S pre-treatment & 58 & $48.32(10.22)$ & $48.59(11.93)$ & $48.45(10.95)$ & $.926(\mathrm{NS})$ \\
\hline STAI-T pre-treatment & 58 & $43.48(10.34)$ & $41.37(11.41)$ & $42.50(10.81)$ & $.462(\mathrm{NS})$ \\
\hline PSS post-treatment & 52 & $53.00(15.40)$ & $55.91(13.90)$ & $54.29(14.69)$ & $.483(\mathrm{NS})$ \\
\hline STAI-S post-treatment & 52 & $38.62(9.44)$ & $39.52(8.61)$ & $39.02(9.01)$ & $.724(\mathrm{NS})$ \\
\hline STAI-T post-treatment & 52 & $37.10(8.81)$ & $37.91(7.95)$ & $37.46(8.37)$ & $.733(\mathrm{NS})$ \\
\hline Patient satisfaction & 58 & $3.41(.44)$ & $2.82(.58)$ & $3.14(0.58)$ & $.000 * * *$ \\
\hline WAI & 58 & $3.51(.69)$ & $3.05(.72)$ & $3.30(0.74)$ & $.016 *$ \\
\hline WAI task & 58 & $3.06(.80)$ & $2.23(.86)$ & $2.68(.92)$ & $.000 * * *$ \\
\hline WAI goal & 58 & $3.53(.70)$ & $3.06(.80)$ & $3.31(.78)$ & $.021 *$ \\
\hline WAI bond & 58 & $3.95(1.06)$ & $3.86(.85)$ & $3.91(.96)$ & .449 (NS) \\
\hline WAI after module 2 & 42 & $3.42(.71)$ & $2.95(.70)$ & $3.21(0.74)$ & $.041 *$ \\
\hline WAI after module 3 & 41 & $3.48(.71)$ & $2.96(.77)$ & $3.24(0.77)$ & $.032 *$ \\
\hline WAI after module 4 & 39 & $3.75(.59)$ & $3.34(.73)$ & $3.59(0.67)$ & $.060(\mathrm{NS})$ \\
\hline WAI after module 5 & 37 & $3.67(.87)$ & $3.37(.69)$ & $3.55(0.81)$ & $.273(\mathrm{NS})$ \\
\hline
\end{tabular}

Note: NS, Not significant; ${ }^{*} \mathrm{p}<.05 ; * * * \mathrm{p}<.001$

\section{Associations between working alliance and the outcome parameters stress/anxiety reductionand patient satisfaction.}

Table IV reveals the correlations of the WAI scores and the PSS, STAI-S and STAI-T residual gain scores. Significant correlations could be found between PSSand STAI-T residual gain scores and the overall WAI as well asbetween all three stress/anxiety reductionoutcomes and the WAI subscale task and goal in the IB-CBSM condition (c.f. Table III). Furthermore, the STAI-T residual gain score showed a significant correlation with the WAI subscale bond. In the control condition no significant correlations could be measured between WAI scores and 
the stress/anxiety reductionparameters. Patient satisfaction shows significant associations with the overall WAI and the WAI subscale task and goal in both conditions. Again no significant correlation could be recorded between satisfaction and the bond subscale (c.f.Table III).

Table IV: Correlations of the WAI scores with the PSS, STAI-S and STAI-T residual gain score as well as patient satisfaction in the IB-CBSM and control condition

\begin{tabular}{lllllllll}
\hline Variable & \multicolumn{2}{l}{ PSS residual gain score } & \multicolumn{2}{c}{ STAI-S residual gain score } & \multicolumn{2}{c}{ STAI-T residual gain score } & \multicolumn{2}{c}{ Patient satisfaction } \\
& IB-CBSM & Control & IB-CBSM & Control & IB-CBSM & Control & IB-CBSM & Control \\
\hline WAI & $.451^{*}$ & .331 & .352 & .003 & $.501^{* *}$ & .019 & $.684^{* *}$ & $.428^{*}$ \\
WAI task & $.528^{* *}$ & .296 & $.480^{* *}$ & -.146 & $.457^{*}$ & .052 & $.776^{* *}$ & $.447^{*}$ \\
WAI goal & $.575^{* *}$ & .243 & $.418^{*}$ & .046 & $.484^{* *}$ & -.054 & $.647^{* *}$ & $.612^{* *}$ \\
WAI bond & .007 & .275 & .029 & .134 & $.391^{*}$ & .051 & .300 & .066 \\
\hline
\end{tabular}

Note: $* \mathrm{p}<.05 ; * *<.01$

\section{Predictive value of working alliance, symptom reduction and group for satisfaction}

WAI was a significant predictor of patient satisfaction $\left(\mathrm{R}^{2}=.398, \mathrm{~F}(1,50)=33.060, \mathrm{p}<.001\right)$.In the overall regression model of WAI, group and symptom reduction, WAIwas predictive for the criterion patient satisfaction $(\beta=.455, \mathrm{t}(50)=4.191, \mathrm{p}<.001)$. Also, the IB-CBSM condition was significantly predictive for patient satisfaction $(\beta=.399, \mathrm{t}(50)=3.930, \mathrm{p}<.001)$. Symptom reduction was not a significant predictor in the overall model $(\beta=.149, \mathrm{t}(50)=1.442, \mathrm{p}=.156$; Table V).

Table V: Summary of Hierarchical Linear Regression for patient satisfaction $(\mathrm{N}=52)$

\begin{tabular}{llllll}
\hline Variable & $\mathrm{B}$ & $\mathrm{SE}(\mathrm{B})$ & $\beta$ & $\mathrm{t}$ & Sig. (p) \\
\hline WAI & .338 & .081 & .455 & 4.191 & .000 \\
IB-CBSM & .413 & .105 & .399 & 3.930 & .000 \\
Symptom reduction & .003 & .002 & .149 & 1.442 & .156 \\
\hline
\end{tabular}

Note: $\mathrm{R}^{2}=.554$

To test the mediating role of working alliance for patient satisfaction, amediator analysis was performed. Group condition was positively related to patient satisfaction $(\beta=.213$, 
$\mathrm{t}(56)=4.383, \mathrm{p}<.001)$ and WAI $(\beta=.462, \mathrm{t}(56)=2.477, \mathrm{p}=.016)$. Additionally, the proposed mediator WAI was positively relatedwith patient satisfaction $(\beta=.169, \mathrm{t}(56)=6.347, \mathrm{p}<.001)$. Results confirmed the partial mediating role of WAI regarding the relation between group condition and patient satisfaction $(\beta=.079, \mathrm{CI}=.022$ to .174$)$. A partial mediation of WAI was confirmed since the direct effect of group condition on patient satisfaction controlling for WAI remains significant $(\beta=.135, t(56)=3.434, p=.001$; Figure 2$)$.

Figure 2: Indirect effect of group on patient satisfaction through working alliance

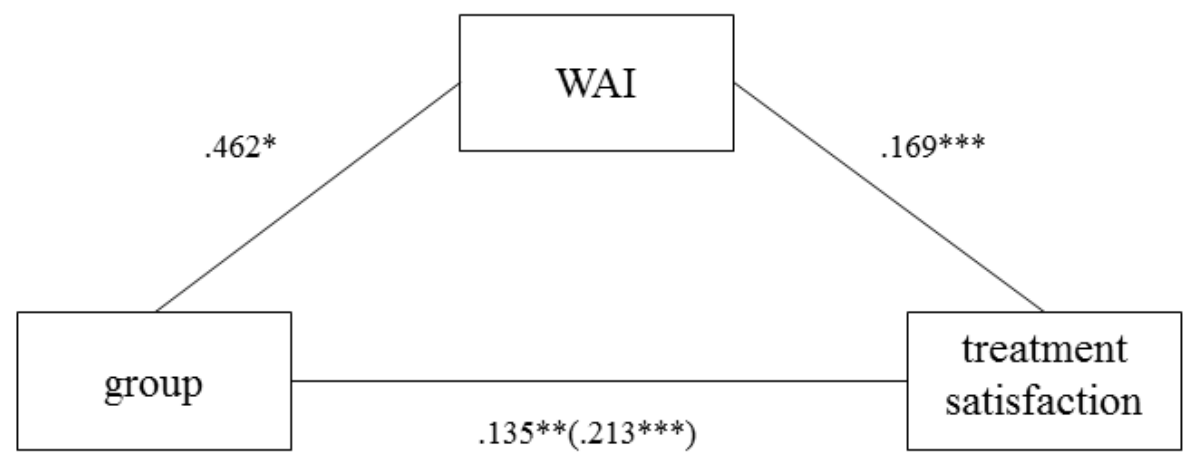

Note: $* \mathrm{p}<.05 ; * * \mathrm{p}<.01 ; * * * \mathrm{p}<.001$

A two-way analysis of variance showed a main effect of low vs. high WAIand group condition (except module 5)on patient satisfaction over the program process (module 2:WAI_splitF $(1,38)=7.593, \quad \mathrm{p}=.009, \quad \operatorname{groupF}(1,38)=5.255, \quad \mathrm{p}=.028 ;$ module 3:WAI_split $\mathrm{F}(1,37)=8.960, \mathrm{p}=.005, \operatorname{group} \mathrm{F}(1,37)=7.273, \mathrm{p}=.010 ;$ module 4:WAI_split $\mathrm{F}(1,35)=11.345$, $\mathrm{p}=.002, \operatorname{groupF}(1,35)=17.005, \quad \mathrm{p}<.001 ; \quad$ module $\quad$ 5:WAI_split $\quad \mathrm{F}(1,33)=10.812$, $\mathrm{p}=.002, \operatorname{group} \mathrm{F}(1,33)=3.835, \mathrm{p}=.059)$; i.e., women with high WAI ratings and women in the IB-CBSM conditionhad higherpatient satisfaction ratings(module 2: high WAI M=3.41, $\mathrm{SD}=.48$, IB-CBSM $\mathrm{M}=3.39, \mathrm{SD}=.44$; module 3 : high WAI $\mathrm{M}=3.43, \mathrm{SD}=.53$, IB-CBSM $\mathrm{M}=3.39, \mathrm{SD}=.46$; module 4: high WAI $\mathrm{M}=3.53, \mathrm{SD}=.46$, IB-CBSM $\mathrm{M}=3.50, \mathrm{SD}=.43$; module 5: high WAI $\mathrm{M}=3.49, \mathrm{SD}=.48, \mathrm{IB}-\mathrm{CBSM} \mathrm{M}=3.41, \mathrm{SD}=.44$ ), whereas women with lowWAI 
ratingsand women in the control condition had lower patient satisfactionratings throughout the program(module 2: low WAI $\mathrm{M}=2.97, \mathrm{SD}=.37$, control $\mathrm{M}=3.00, \mathrm{SD}=.45$; module 3: low WAI $\mathrm{M}=2.84, \mathrm{SD}=.56$, control $\mathrm{M}=2.79, \mathrm{SD}=.63$; module 4: low WAI $\mathrm{M}=2.99, \mathrm{SD}=.43$, control $\mathrm{M}=2.90, \mathrm{SD}=.43$; module 5: low WAI $\mathrm{M}=2.95, \mathrm{SD}=.39$, control $\mathrm{M}=2.97, \mathrm{SD}=.51$ ). The interaction effect was non-significant over all modules.

\section{DISCUSSION}

The aim of this study was to analyze stress/anxiety reduction, patient satisfaction and patient's working alliance of women in IB-CBSM.It wasexpected thatthe use of thenonspecificdistractionexercises ofthe control condition actuallydo not meet theneeds of theclientto the same extent like in the IB-CBSM condition. Thisis also underlined bytheresults ofpatientsatisfactionwhichissignificantly lower in thecontrol condition. However, it is surprising that the control group, despite non-agreement with individual needs and low WAI and satisfaction rating, benefitsin a similar manneras theIB-CBSM regarding stress/anxiety reduction. The most obviousexplanation for this effect isthat in the control condition, the reductionof stress and anxietyseems to workin a different waythan in theIB-CBSMcondition. Thecontrol condition, by definition, was not designedto meetthe needsof anxious women with PTL, butbased solely on the concept of distraction. Some studies, however, showed that specificallyuseddistractionexercises can also show positiveeffects regarding psychological distress $(41,42)$ even in a group of women with PTL(43). However,it must be notedthatin bothconditionsspontaneousremissioncouldhave led to areductionin symptoms.Despite the equivalence of IB-CBSM or the control condition in terms of efficacy, it is importantto consider patientsatisfaction when choosing interventions for a target group. In our study, IBCBSM clearly outperforms the control condition in this regard.

As explained,an adapted version of the WAI-SR was used, which specifically distinguished between the agreement with goal and task components of the online program and the working 
alliance with the therapist.Regarding WAI subscales, results pointed out that the participants in the IB-CBSM group rated working alliance significantly higher in both the task and the goal subscale, whereas the bond scale showed no differences between the groups. This last result indicate that participants in both conditions felt equally well with the therapeutic support that they have received.The associations of working alliance and stress/anxiety reductionin the IB-CBSM showedsignificant correlations predominantly with the task and goal subscale.However this does not mean that the alliance with the therapist is not important, because for women who participate in the study it could have been obvious that the distraction exercise in the control condition have nothing to do with the actual stress/anxiety reduction. Nevertheless the observedfinding,thattheaccordance of the program withtaskandgoal components is crucial for therapy outcomeunderlines that in the development of guided selfhelp approaches, the fit between the intervention program and the needs of the participants seems especially important. Recent advancements in the fieldof internetbasedinterventionsfollow this attemptinform of tailoring program elements in relation tothe problems and needsof the participants (35).Also in regard to the recent study some more tailored program elements would have been helpful. Afirststep in this directioncould bethe provision of additional moduleswith detailed information aboutcomorbidsymptoms (e.g. sleep problems) for processing depending on the individual needs.

Regarding patient satisfaction it was shown thatWAI explained nearly $40 \%$ of the variance in patientsatisfaction. The strong predictive effectof working allianceon satisfaction with the programis in line with the results of Leibert et al. (44), who showed that working alliance significantly predicted respondent satisfaction with internet-based treatments. This result substantiates the importance ofworking alliancefor satisfaction with psychotherapeutic treatments and was further supported by the partial mediation ofworking allianceonthe relationship between group condition and patient satisfaction. Therefore, it can be assumedin line with Hirsh et al.(17) that more satisfying therapeutic interventions requireworking 
alliance parameters, e.g. a high level of agreement with the treatment. The analysis of associations with the WAI subscales indicated also with regard to patient satisfaction significant correlations with task and goal components. To learn moreabout the role of the WAI subscales, it could be interesting in further analysis to look at the specific predictive and mediating value of the WAI subscales separately.

In accordance with the results of McLeod (19)and Hirsh et al. (17), the present study has shown that the relation between these factors ofworking alliance and patient satisfaction isstronger than the effect of the actual symptom reduction on patient satisfaction. This underlines the assumption that the measures of agreement with working alliance parameters actually could have a stronger influence on satisfaction than the objectively quantifiable effectiveness in terms of symptom reduction. Women with high WAI ratings over the program as well as women in the IB-CBSM reported significantly better patient satisfaction scores than women who had low WAI ratings or women who were assigned to the control condition. Interestingly, this effect was observable as early as the second treatment module.

\section{Limitations}

With regard to our sample size, our results are to be considered as preliminaryand althoughnodifferencesbetweencompletersand drop-outs could be found the high dropoutrate(nearly $38 \%$ ) of our study should be mentioned as a further limitation.Drop-out reasons were birth before pre-treatment measure, pregnancy complications, lack of time and elusiveness of the participants throughout the program. Another limitation is that the wide gestation age included in the study and the stressors which vary depending on gestational age may result in different stress levels. At the stageofearly pregnancyuncertainty andfear of anabortion are predominantly. During pregnancy these stress factors often change and concernsabout the child's health, fear of childbirthorthepostpartum period become increasingly important and can enhance the perceived stress level. Furthermorethe inclusionof awaiting list control group into the study design would have been promising to provide more 
detailed information about the progress of psychological distress parameters.

\section{Conclusion}

To our knowledge the recent study is the first to evaluate an intervention with an IB-CBSM for pregnant women with PTL. Ourresults, althoughpreliminarydue to thesmallsample size, indicatethatwith anIB-CBSM adequate psychological supportcan be provided to these women.The results highlight the importance of the working alliance and especially the agreement with goal and task components for internet-based stress managementbothwith respect to stress/anxiety reductionas well as patientsatisfaction. Besides the circumstancethat thefit with theprogram seems to be essential, it is worthy to point outthat building up agoodworking allianceisgenerally crucial but especiallyif theinterventionisactuallygeared to thespecificneeds of thetarget population.

\section{ACKNOWLEDMENTS}

Wewouldparticularlylike to thank all the women who participated in the study, as well as the medical staff, the study midwifes and the research assistants contributing to this study. The research project is supported by the Swiss National Science Foundation. Grant number:

CR13I1_135060. Trial numbers of the research project: Swiss National Science Foundation (SNSF): Registration number: 135060 and Forsbase online Research inventory: Registration number: 11134 


\section{REFERENCES}

1. World Health Organization W. Preterm birth

http://www.who.int/mediacentre/factsheets/fs363/en/2014.

2. Challis JRG, Matthews SG, Gibb W, Lye SJ. Endocrine and paracrine regulation of birth at term and preterm. Endocrine reviews. 2000;21(5):514-50. Epub 2000/10/21. doi: 10.1210/edrv.21.5.0407. PubMed PMID: 11041447.

3. Goldenberg RL, Culhane JF, Iams JD, Romero R. Epidemiology and causes of preterm birth. Lancet. 2008;371(9606):75-84. Epub 2008/01/08. doi: 10.1016/s01406736(08)60074-4. PubMed PMID: 18177778.

4. Ruiz RJ, Fullerton J, Dudley DJ. The interrelationship of maternal stress, endocrine factors and inflammation on gestational length. Obstetrical \& gynecological survey. 2003;58(6):415-28. Epub 2003/05/31. doi: 10.1097/01.ogx.0000071160.26072.de. PubMed PMID: 12775946.

5. Dunkel Schetter C, Glynn LM. Stress in pregnancy: Empirical evidence and theoretical issues to guide interdisciplinary research. In: A CRB, editor. The handbook of stress science: Springer; 2010. p. 321-43.

6. Kaluza G. Stressbewältigung - Trainingsmanual zur psychologischen Gesundheitsförderung. Heidelberg: Springer Medizin Verlag; 2004.

7. Schneiderman N, Antoni MH, Saab PG, Ironson G. HEALTH PSYCHOLOGY: Psychosocial and Biobehavioral Aspects of Chronic DiseaseManagement. Annu Rev Psychol. 2001;52:555-80.

8. Fontein-Kuipers YJ, Nieuwenhuijze MJ, Ausems M, Bude L, de Vries R. Antenatal interventions to reduce maternal distress: a systematic review and meta-analysis of randomised trials. BJOG : an international journal of obstetrics and gynaecology. 2014;121(4):389-97. Epub 2014/01/09. doi: 10.1111/1471-0528.12500. PubMed PMID: 24397691.

9. Spek V, Cuijpers P, Nyklicek I, Riper H, Keyzer J, Pop V. Internet-based cognitive behaviour therapy for symptoms of depression and anxiety: a meta-analysis. Psychological medicine. 2007;37(3):319-28. Epub 2006/11/23. doi: 10.1017/s0033291706008944. PubMed PMID: 17112400.

10. Barak A, Hen L, Boniel-Nissim M, Shapira N. A comprehensive review and a metaanalysis of the effectiveness of Internet-based psychotherapeutic interventions. J Technol Hum Serv. 2008;26:109-60.

11. Andersson G, Cuijpers P. Internet-based and other computerized psychological treatments for adult depression: a meta-analysis. Cognitive behaviour therapy. 2009;38(4):196-205. Epub 2010/02/26. doi: 10.1080/16506070903318960. PubMed PMID: 20183695.

12. Lebow J. Consumer satisfaction with mental health treatment. Psychological bulletin. 1982;91(2):244-59. Epub 1982/03/01. PubMed PMID: 7071260.

13. George SZ, Robinson ME. Preference, expectation, and satisfaction in a clinical trial of behavioral interventions for acute and sub-acute low back pain. The journal of pain : official journal of the American Pain Society. 2010;11(11):1074-82. Epub 2010/05/15. doi: 10.1016/j.jpain.2010.02.016. PubMed PMID: 20466596; PubMed Central PMCID: PMCPmc2921587.

14. Vermeire E, Hearnshaw H, Van Royen P, Denekens J. Patient adherence to treatment: three decades of research. A comprehensive review. Journal of clinical pharmacy and therapeutics. 2001;26(5):331-42. Epub 2001/10/27. PubMed PMID: 11679023.

15. Bennett JK, Fuertes JN, Keitel M, Phillips R. The role of patient attachment and working alliance on patient adherence, satisfaction, and health-related quality of life in 
lupus treatment. Patient education and counseling. 2011;85(1):53-9. Epub 2010/09/28. doi: 10.1016/j.pec.2010.08.005. PubMed PMID: 20869188.

16. Jackson JL, Chamberlin J, Kroenke K. Predictors of patient satisfaction. Social science \& medicine (1982). 2001;52(4):609-20. Epub 2001/02/24. PubMed PMID: 11206657.

17. Hirsh AT, Atchison JW, Berger JJ, Waxenberg LB, Lafayette-Lucey A, Bulcourf BB, et al. Patient satisfaction with treatment for chronic pain: predictors and relationship to compliance. The Clinical journal of pain. 2005;21(4):302-10. Epub 2005/06/14. PubMed PMID: 15951647.

18. McCracken LM, Klock PA, Mingay DJ, Asbury JK, Sinclair DM. Assessment of satisfaction with treatment for chronic pain. Journal of pain and symptom management. 1997;14(5):292-9. Epub 1997/12/11. PubMed PMID: 9392923.

19. McLeod BD. Relation of the alliance with outcomes in youth psychotherapy: a metaanalysis. Clinical psychology review. 2011;31(4):603-16. Epub 2011/04/13. doi: 10.1016/j.cpr.2011.02.00310.1016/j.cpr.2011.02.001. PubMed PMID: 21482319.

20. Horvath AO. The alliance. Psychotherapy: Theory, Research, Practice, Training. 2001;38(4):365-72. doi: doi:10.1037/0033-3204.38.4.365.

21. Horvath AO, Del Re AC, Fluckiger C, Symonds D. Alliance in individual psychotherapy. Psychotherapy (Chicago, Ill). 2011;48(1):9-16. Epub 2011/03/16. doi: 10.1037/a0022186. PubMed PMID: 21401269.

22. Sucala M, Schnur JB, Constantino MJ, Miller SJ, Brackman EH, Montgomery GH. The therapeutic relationship in e-therapy for mental health: a systematic review. Journal of medical Internet research. 2012;14(4):e110. Epub 2012/08/04. doi: 10.2196/jmir.2084. PubMed PMID: 22858538; PubMed Central PMCID: PMCPmc3411180.

23. Wagner B, Maercker A. Psychotherapie im Internet - Wirksamkeit und Anwendungsbereiche. Psychotherapeutenjournal. 2011;1:33-42

24. Knaevelsrud C, Maercker A. Does the quality of the working alliance predict treatment outcome in online psychotherapy for traumatized patients? Journal of medical Internet research. 2006;8(4):e31. Epub 2007/01/11. doi: 10.2196/jmir.8.4.e31. PubMed PMID: 17213049; PubMed Central PMCID: PMCPmc1794007.

25. Scherer S, Urech C, Hosli I, Tschudin S, Gaab J, Berger T, et al. Internet-based stress management for women with preterm labour-a case-based experience report. Archives of women's mental health. 2014;17(6):593-600. Epub 2014/08/16. doi: 10.1007/s00737-014-0454-3. PubMed PMID: 25123471.

26. Cohen S, Kamarck T, Mermelstein R. A global measure of perceived stress. Journal of health and social behavior. 1983;24(4):385-96. Epub 1983/12/01. PubMed PMID: 6668417.

27. Spielberger CD, Gorsuch RL, Lushene R, Vagg PR, Jacobs GA. Manual for the statetrait anxiety inventory. Palo Alto: Consulting Psychologists Press; 1983.

28. Laux L, Glanzmann P, Schaffner P, Spielberger CD. Das state-trait-angstinventar. Weinheim: Beltz; 1981.

29. Schmidt J, Lamprecht F, Wittmann WW. [Satisfaction with inpatient management. Development of a questionnaire and initial validity studies]. Psychotherapie, Psychosomatik, medizinische Psychologie. 1989;39(7):248-55. Epub 1989/07/01. PubMed PMID: 2762479.

30. Attkisson CC, Zwick R. The client satisfaction questionnaire. Psychometric properties and correlations with service utilization and psychotherapy outcome. Evaluation and program planning. 1982;5(3):233-7. Epub 1981/12/12. PubMed PMID: 10259963.

31. Hatcher RL, Gillaspy JA. Development and validation of a revised short version of the Working Alliance Inventory. Psychotherapy Research. 2006;16(1):12-25. 
32. Bordin ES. The generalizability of the psychoanalytic concept of the working alliance. Psychotherapy: Theory, Research \& Practice. 1979;16(3):252-60.

33. Wilmers F, Munder T, Leonhart R, Herzog T, Plassmann R, Barth J, et al. Die deutschsprachige Version des Working Alliance Inventory - short revised (WAI-SR) Ein schulenübergreifendes, ökonomisches und empirisch validiertes Instrument zur Erfassung der therapeutischen Allianz. Klin Diagnostik u Evaluation. 2008;1:343-58.

34. Munder T, Wilmers F, Leonhart R, Linster HW, Barth J. Working Alliance InventoryShort Revised (WAI-SR): psychometric properties in outpatients and inpatients. Clinical psychology \& psychotherapy. 2010;17(3):231-9. Epub 2009/12/17. doi: 10.1002/cpp.658. PubMed PMID: 20013760.

35. Berger T, Boettcher J, Caspar F. Internet-based guided self-help for several anxiety disorders: a randomized controlled trial comparing a tailored with a standardized disorder-specific approach. Psychotherapy (Chicago, Ill). 2014;51(2):207-19. Epub 2013/09/18. doi: 10.1037/a0032527. PubMed PMID: 24041199.

36. Preacher KJ, Hayes AF. Asymptotic and resampling strategies for assessing and comparing indirect effects in multiple mediator models. Behavior research methods. 2008;40(3):879-91. Epub 2008/08/14. PubMed PMID: 18697684.

37. Cohen J. Statistical power analysis for the behavioral sciences. Hillsdale: Erlbaum; 1988.

38. Tempier R, Pawliuk N, Perreault M, Steiner W. Satisfaction with clinical case management services of patients with long-term psychoses. Community mental health journal. 2002;38(1):51-9. Epub 2002/03/15. PubMed PMID: 11892856.

39. Greenwood N, Key A, Burns T, Bristow M, Sedgwick P. Satisfaction with in-patient psychiatric services. Relationship to patient and treatment factors. The British journal of psychiatry : the journal of mental science. 1999;174:159-63. Epub 1999/04/22. PubMed PMID: 10211171.

40. Jasper K, Weise C, Conrad I, Andersson G, Hiller W, Kleinstäuber M. The working alliance in a randomized controlled trial comparing Internet-based self-help and faceto-face cognitive behavior therapy for chronic tinnitus. Internet Interv. 2014;1(2):4957.

41. Lahmann C, Schoen R, Henningsen P, Ronel J, Muehlbacher M, Loew T, et al. Brief relaxation versus music distraction in the treatment of dental anxiety: a randomized controlled clinical trial. Journal of the American Dental Association (1939). 2008;139(3):317-24. Epub 2008/03/04. PubMed PMID: 18310736.

42. Priem JS, Solomon DH. Comforting Apprehensive Communicators: The Effects of Reappraisal and Distraction on Cortisol Levels Among Students in a Public Speaking Class. Commun Q 2009;57:259-81.

43. Van Zuuren FJ. The effects of information, distraction and coping style on symptom reporting during preterm labor. Psychology and Health. 1998;13:49-54.

44. Leibert T, Archer Jr. J, Munson J, York G. An Exploratory Study of Client Perceptions of Internet Counseling and the Therapeutic Alliance. Journal of Mental Health Counseling. 2006;28(1):69-83. 


\section{APPENDICES}

A Adapted Client Satisfaction Questionnaire

[1]="Wie beurteilen Sie die Qualität des TOPAS Trainingsprogramms?";

[2]="Haben Sie mit dem TOPAS Trainingsprogramm eine Behandlung erhalten, die Sie wollten?";

[3]="In welchem Masse hat das TOPAS Trainingsprogramm Ihren Bedürfnissen entsprochen?";

[4]="Würden Sie einer Freundin das TOPAS Trainingsprogramm empfehlen, wenn sie ähnliche Hilfe benötigen würde?";

[5]="Wie zufrieden sind Sie mit dem Ausmass der Hilfe, welche Sie erhalten haben?"; [6]="Hat das TOPAS Trainingsprogramm Ihnen dabei geholfen, angemessener mit Ihren Problemen umzugehen?";

[7]="Wie zufrieden sind Sie mit dem Programm insgesamt?";

[8]="Würden Sie das TOPAS Programm wieder nutzen?";

B Adapted Working Alliance Inventory

$[1]=$ "Durch das TOPAS Online Trainingsprogramm ist mir klarer geworden, wie ich mich verändern kann."

[2]="Was ich im TOPAS Trainingsprogramm mache, eröffnet mir neue Sichtweisen auf mein Problem."

[3]="Ich glaube meine Psychologin mag mich."

[4]="Ich weiß, was ich als Ergebnis des TOPAS Trainingsprogramms erwarten kann."

$[5]=$ "Meine Psychologin und ich achten einander."

[6]="Die Ziele des TOPAS Trainingsprogramms stimmen mit meinen Zielen überein."

[7]="Ich spüre, dass mich meine Psychologin schätzt."

$[8]="$ Die Ziele des TOPAS Trainingsprogramms sind wichtige Ziele für mich."

[9]="Meine Psychologin interessiert sich wirklich für mein Wohlergehen."

$[10]=" I c h$ spüre, dass das, was ich im TOPAS Trainingsprogramm tue, mir helfen wird, die von mir gewünschten Veränderungen zu erreichen."

[11]="Das TOPAS Trainingsprogramm hilft mir zu verstehen, welche Veränderungen gut für mich wären."

[12]="Ich glaube, dass es richtig ist, wie ich im Rahmen des TOPAS Trainingsprogramms an meinem Problem arbeite." 